\title{
Detection of proteolytic cleavages of diabetes-associated protein IA-2B in the pancreas and the brain using novel anti-IA-2ß monoclonal antibodies
}

\author{
TOMIKO KAWAKAMI ${ }^{1}$, KEIICHI SAEKI ${ }^{1}$, NATSUMI TAKEYAMA ${ }^{1}$, GUOYING WU $^{1}$, AKIKAZU SAKUDO ${ }^{1}$, \\ YOSHITSUGU MATSUMOTO $^{1}$, TOSHIHARU HAYASHI ${ }^{2}$ and TAKASHI ONODERA ${ }^{1}$ \\ ${ }^{1}$ Department of Molecular Immunology, School of Agricultural and Life Sciences, University of Tokyo, \\ Bunkyo-ku, Tokyo 113-8657; ${ }^{2}$ Department of Veterinary Pathology, School of Agriculture, \\ Yamaguchi University, Yamaguchi 753-8515, Japan
}

Received November 21, 2006; Accepted December 22, 2006

\begin{abstract}
Insulinoma-associated protein (IA)-2ß, an inactive member of the protein-tyrosine phosphatase (PTP) family, is a major autoantigen in type- 1 diabetes mellitus. IA- $2 \beta$ exists mainly in a $60-\mathrm{kDa}$ form, and is frequently located in the dense-core secretory vesicles of pancreatic $B$ cells. As IA-2 $\beta$ gene-deficient mice exhibit impaired insulin secretions, IA$2 \beta$ is probably involved in insulin secretions. In the present study, we characterized the major forms of IA- $2 B$ in the brain and pancreas of normal and non-obese diabetic (NOD) mice. Novel monoclonal antibodies (mAbs) against IA- $2 \beta$ revealed that this brain protein was of multiple compositions incorporating the 60-, 64-, 67- and 71-kDa forms, which were designated as IA-2B60, IA-2ß64, IA-2ß67 and IA-2ß71, respectively. On the contrary, only the $60-\mathrm{kDa}$ isoform of IA$2 B$ was expressed in the mouse pancreas and in the mouse pancreatic $B$ cell line, MIN6. Sequence analyses revealed that IA-2ß60, IA-2ß64 and IA-2ß71 (brain-derived immunoprecipitated IA- $2 \beta$ isoforms) contained alternative $\mathrm{NH}_{2}$ termini starting from $\mathrm{Glu}^{489}, \mathrm{Ala}^{464}$, and $\mathrm{Ser}^{414}$, respectively, while IA-2B60 (an MIN6-derived immunoprecipitated IA-2ß isoform) contained those from $\mathrm{Glu}^{489}$. Consistent with the lack of an $\mathrm{NH}_{2}$-terminal region of IA-2ß, the isoforms were recognized by their respective mAbs characterized with different epitope regions. Furthermore, Western blotting and immunohistochemistry demonstrated that NOD mice expressed similar isoforms present in the brains and pancreatic islets of C57BL/6J, BALC/CA and ICR mice, accordingly. Taken together, these results suggest that IA- $2 B$ undergoes at least three distinct proteolytic cleavages.
\end{abstract}

Correspondence to: Professor Takashi Onodera, Department of Molecular Immunology, School of Agricultural and Life Sciences, University of Tokyo, Bunkyo-ku, Tokyo 113-8657, Japan

E-mail: aonoder@mail.ecc.u-tokyo.ac.jp

Key words: autoantigen, autoimmunity, immunoprecipitation, pancreas islet, type-1 diabetes

\section{Introduction}

Insulinoma-associated protein (IA)-2ß, which has recently been identified as a novel member of a new family of the transmembrane receptor-type PTP-like proteins (1-4), is expressed differently in various animal species; i.e. mouse IA-2B (mIA-2 $\beta$ ), rat IA-2ß and human IA- $2 \beta(1,2,5)$. The PTP domain of IA-2ß in animal species is highly conserved (6). IA-2B mRNA expression is restricted within neuroendocrine tissues such as the brain and pancreatic islets $(1,2,5)$.

Mouse IA-2b (mIA-2ß) is a transmembrane protein (Fig. 1) composed of 1,001 amino acids (1). The intracellular domain consists of a single PTPase homology region extending from residues 756 to 990 with several putative phosphorylation sites. The extracellular domain consists of a signal peptide with one predicted cleavage (KK) site and one $N$-glycosylation site. Due to substitution of the consensus alanine with aspartate at the catalytic site (7), IA- $2 \beta$ does not show phosphatase activity, although it is a member of the PTP family. In a similar functional manner, another PTP-like molecule, IA-2, shows no phosphatase activity (8) either. IA$2 B$ and IA-2 are classified as novel transmembrane PTP-like proteins in a new receptor-type PTP family characterized by the lack of enzymatic (phosphatase) activity (9). However, the physiological function(s) of IA-2ß remains unclear.

Hitherto, IA-2ß has been known to act as a major autoantigen in type- 1 diabetes mellitus $(1,5)$. Type- 1 diabetes is a $\mathrm{T}$ cell-mediated autoimmune disease, where $\beta$ cells of the pancreatic islets of Langerhans are destroyed (10). Approximately $50 \%$ of newly diagnosed type- 1 diabetics have IA-2ß-reactive autoantibodies, which are expressed years before clinical onset (11). The cause of breakdown in the immunological tolerance and the role of IA- $2 B$ in the pathogenesis of type- 1 diabetes are unknown as yet. However, a better understanding of type- 1 diabetes will be achieved if the physiological function and role of IA-2B are clarified. The extensively employed animal model of type- 1 diabetes, the non-obese diabetic (NOD) mouse, was used as the experimental model in our present study to provide invaluable insights to understand the physiological perspectives of IA-2ß. 
As a first step in the elucidation of the role of IA- $2 B$ in neuroendocrine cells, we analyzed mIA- $2 \beta$ expression in the mouse brain using novel monoclonal antibodies (mAbs) against mIA- $2 \beta$ to detect novel IA- $2 \beta$ isoforms. In the mouse brain, IA-2ß-specific bands detected by Western blotting were named after their respective molecular weights; viz., the 60-, 63-, 67- and 71-kDa isoforms were respectively known as IA-2ß60, IA-2ß64, IA-2ß67 and IA-2ß71. Three types of mAbs were developed to classify the IA-2B isoforms: type- 1 mAb located IA-2B67 and IA-2B71; type- 2 mAb detected IA-2ß64, IA-2ß67 and IA-2ß71; while type- $3 \mathrm{mAb}$ detected IA-2ß60, IA-2ß67, IA-2ß67 and IA-2ß71, accordingly.

Epitope-mapping analyses showed that the $\mathrm{mAb}$ indicated different but specific epitope regions; type-1, -2 and -3 mAbs recognized amino acids 456-470, 471-493 and 505-534, respectively. It was suggested that $I A-2 \beta$ in the mouse brain is composed of at least four isoforms. Moreover, IA-2ß60 and IA-2B64 were processed within the region of amino acids 456-534. IA-2ß in MIN6, a mouse pancreatic $\beta$ cell line, was detected by only type- $3 \mathrm{mAb}$ but not by type- 1 and $-2 \mathrm{mAbs}$. In other words, IA-2ß64, IA-2ß67 and IA-2ß71 were probably not produced in pancreatic $B$ cells. As IA-2B60 was also detected by only type- $3 \mathrm{mAb}$, processing of IA- $2 \beta$ in the $\beta$ cell line might resemble that of IA-2ß60. Consequently, the identification of IA- $2 B$ isoforms in the brain indicated that IA-2ß may exist in multiple forms to perform the many multifaceted brain functions.

IA- $2 \beta$ is likely to undergo several processes that might eventually affect its maturation and function. For understanding the function and processing mechanism(s) of IA-2 $B$ in the brain, factors affecting the production of mIA- $2 B$ isoforms were determined in this study. The present study established evidence that mIA-2 3 was subjected to at least three distinct proteolytic cleavages. Furthermore, the isoform expression pattern in the NOD mouse was studied to investigate antigen abnormalities in type-1 diabetes. There were no abnormal isoform expression patterns in the brain and pancreatic $\beta$ cells in the NOD mouse.

\section{Materials and methods}

Animals. Using $I A-2 \beta^{-/-}$and $I A-2 \beta^{+/-}$mice developed at the National Institute of Health, USA (12), the latter were mated among themselves to produce $I A-2 \beta^{+/+}$littermates. $I A-2 \beta^{-1-}$ mice and generated $I A-2 \beta^{+/+}$mice were used in this study. NOD/Shi Jic (NOD), ICR/Jcl (ICR), BALB/cAJcl (BALB) and C57BL6/J (C57BL) (CLEA Japan, Inc., Tokyo) and BALB/c Slc-nи (NUDE) mice (Japan SLC, Inc., Tokyo) were used in the experiments for testing and references.

Preparation of recombinant protein. Polymerase chain reaction (PCR) amplified mIA-2ß DNA fragments with listed primers (Table I), using the mIA- $2 \beta \mathrm{cDNA}$ as a template. Amplified fragments were inserted into the pT7Blue T-vector (Merck Ltd., Tokyo) and then transferred into Escherichia coli XL 10 (Stratagene Japan Co. Ltd., Tokyo). After the plasmids were purified from cultured colonies, the cDNA fragments were isolated from the plasmid by $\mathrm{Nr} u \mathrm{I}$ and $\mathrm{Bg} / \mathrm{II}$ endonuclease digestion. The cDNA fragments were electrophoresed on $1 \%$ agarose gel and subcloned into the PinPointXa-1 vector (Promega Co., Tokyo, Japan) by NruI and $B g l I I$ endonuclease digestion. The vectors were then transferred into Escherichia coli XL-10 to obtain the recombinant IA-2ß proteins [IA2- $B$ (415-717), IA2- 3 (464717), IA2- 3 (489-717)] (Fig. 1). The transformed XL-10 was cultured in liquid media containing $100 \mu \mathrm{g} / \mathrm{ml}$ ampicillin, $34 \mu \mathrm{g} / \mathrm{ml}$ chloramphenicol and $2 \mu \mathrm{M}$ biotin. Protein expression was induced in logarithmically growing bacterial cultures with $100 \mu \mathrm{M}$ isopropyl-thio- $\beta$-D-galactopyranoside for $6 \mathrm{~h}$ at $37^{\circ} \mathrm{C}$. Bacteria were collected by centrifugation

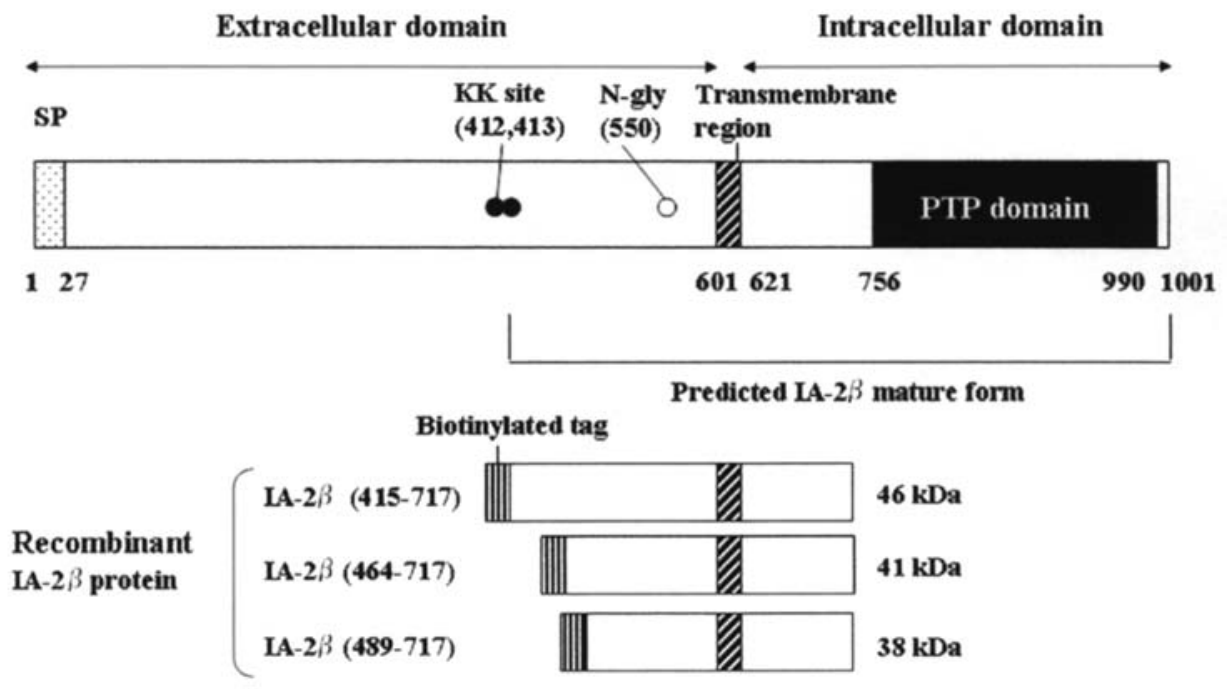

Figure 1. Domain structures of mouse insulinoma-associated protein (mIA)- $2 \beta$ and recombinant IA-2 $\beta$ protein. Based on the primary structure of mIA- $2 \beta$ protein by $L u$ et al (1) in 1996, the residue numbers of amino acids are indicated within the mIA-2ß protein. The signal peptide (SP, stippled column), transmembrane region (hatched column) and protein-tyrosine phosphatase (PTP) domain (closed block) are represented, accordingly. Predicted cleavage (KK site, closed circles) and $N$-linked glycosylation ( $\mathrm{N}$-gly, open circle) site are located within the predicted mature IA-2ß form (bracketed region). Three recombinant IA-2ß proteins, IA-2ß (414-717), IA-2ß (464-717) and IA-2ß (489-717), served as fusion proteins with their biotinylated tags (striped column) and IA-2ß amino acid sequences containing amino acids 414-717, 464-717 and 489-717, respectively. The molecular weights of the respective recombinant IA- $2 \beta$ proteins are indicated on the right end of the blocks. 
Table I. Primers for expression of recombinant IA- $2 \beta$ proteins.

\begin{tabular}{|c|c|c|c|}
\hline & $\begin{array}{l}\text { Recombinant IA- } 2 \beta \text { proteins } \\
\quad \text { (amino acid residues) }\end{array}$ & Primers & Enzymes \\
\hline \multirow[t]{3}{*}{ Forward primers } & IA-2ß (415-717) & 5'-ATTCGCGACAAGTTGTCTGGACTAGGCGCT-3' & $N r u \mathrm{I}$ \\
\hline & IA-2ß (464-717) & 5'-AATCGCGAAGCTCCAGAGTTGTGGGAGGATGAA-3' & NruI \\
\hline & IA-2ß (489-717) & 5'-AATCGCGAAGTGCAGCCTTCTGAGGAACAG-3' & NruI \\
\hline \multirow[t]{3}{*}{ Reverse primers } & IA-2ß (415-717) & & \\
\hline & IA-2ß (464-717) & 5'-AAAGATCTTCAGATCATGTGGCCAGTAGAGATGTC-3' & $B g l I I$ \\
\hline & IA-2ß (489-717) & & \\
\hline
\end{tabular}

$\left(3,000 \times \mathrm{g}, 30 \mathrm{~min}, 4^{\circ} \mathrm{C}\right)$ and dissolved in ultra-pure water before use.

Mouse immunization. The 6xHis tagged IA-2ß (415-1001) recombinant protein using the pRROEX-HTa vector that produced a fusion-protein tagged with the $6 \mathrm{xHis}$ peptide at the $\mathrm{N}$-terminus (produced as described above and purified in accordance with the instructions of Invitrogen Life Technologies, Carlsbad, CA). The 6xHis-tagged IA-2B (4151001) was used as the antigen for immunization (13). IA-2 $\beta^{-1-}$ male mice were immunized intraperitoneally (i.p.) four times at 2-week intervals with $20 \mu \mathrm{g}$ of the antigen. The antigen was mixed with an equal volume of Freund's complete adjuvant (Sigma) for the first immunization attempt, and with Freund's incomplete adjuvant when boosted. Sera from these mice were evaluated by enzyme-linked immunosorbent assay (ELISA) for antibody reactivity immunogen. Once an appropriate antibody response was noted, the animals were given a final booster injection 4 days before splenectomy. Splenocytes were isolated and fused with P3X63Ag8.653 myeloma cells. After hypoxanthine-aminopterin-thymidine (HAT) selection, hybridomas were cultivated in RPMI-1640 supplemented with $15 \%$ heat-inactivated FCS, $5 \%$ P388 cell cultural fluids, $20 \mathrm{U} / \mathrm{ml}$ penicillin and $20 \mu \mathrm{g} / \mathrm{ml}$ streptomycin. Three types of mAbs (clones WT4, KO8 and $\mathrm{KO} 25$ ) were raised from the hybridomas.

Hybridomas. Hybridomas previously cultured in full RPMI1640 (Sigma Aldrich Japan Co. Ltd., Tokyo) contained 15\% fetal bovine serum. The cells were washed and re-suspended with RPMI-1640. NUDE mice were injected i.p. with 3-4x106 hybridomas. The mice were inspected weekly and the peritoneal fluid was removed when ascite development was apparent. Ascite fluid was extracted and filtrated before use. In addition, hybridomas were concurrently cultured in RPMI1640 containing $15 \%$ fetal bovine serum and adapted to grow in $95 \%$ serum-free medium (Hybridoma SFM; Invitrogen Japan Co. Ltd.) and 5\% P388 D $_{1}$ culture supernatant. Isolated mAbs were purified by affinity chromatography with HiTrap Protein G (Amersham Biosciences Co. Ltd., Tokyo) according to the manufacturer's instructions. Briefly, the culture supernatant was loaded onto the column by a perista pump (AC-2110, Atto, Tokyo), and the column was then washed with $20 \mathrm{mM} \mathrm{Na}_{2} \mathrm{PO}_{4}$ ( $\mathrm{pH} \mathrm{7.0)}$ before the mAbs were eluted with $0.1 \mathrm{M}$ glycine- $\mathrm{HCl}(\mathrm{pH}$ 2.7). The protein concentrations of purified antibodies were determined using the DC protein assay kit (Bio-Rad Laboratories Inc., Tokyo).

Cell culture. Cells of MIN6 (a gift from Dr J. Miyazaki of the University of Tokyo) and the mouse pancreatic $\beta$ cell line (14) were separately grown in Dulbecco's modified Eagle medium (DMEM) with $4 \mathrm{mM} \mathrm{L-glutamine} \mathrm{adjusted} \mathrm{to} 1.5 \mathrm{~g} / \mathrm{l}$ sodium bicarbonate and $4.5 \mathrm{~g} / 1$ glucose (Sigma-Aldrich Japan Co.) supplemented with $50 \mu \mathrm{M} 2$-mercaptoethanol and $15 \%$ fetal calf serum (FCS), and maintained in $5 \% \mathrm{CO}_{2} / 95 \%$ air at $37^{\circ} \mathrm{C}$.

Preparation of membrane fractions. All procedures were performed at $4^{\circ} \mathrm{C}$. Tissues were first homogenized in phosphate-buffered saline (PBS) $(137 \mathrm{mM} \mathrm{NaCl}, 2.7 \mathrm{mM}$ $\mathrm{KCl}, 10 \mathrm{mM} \mathrm{Na}_{2} \mathrm{HPO}_{4}$ and $2 \mathrm{mM} \mathrm{KH}_{2} \mathrm{PO}_{4}$ ) and sonicated subsequently. The suspension was centrifuged at $5,000 \times \mathrm{g}$ for $30 \mathrm{~min}$ to remove non-lysed cells, nuclear materials and other cellular debris. The supernatant was further centrifuged at $100,000 \mathrm{xg}$ for $1 \mathrm{~h}$, and the pellets were re-suspended in PBS before centrifugation was repeated at $100,000 \mathrm{xg}$ for $1 \mathrm{~h}$. The membrane fraction was obtained as the pellet.

Western blotting. Membrane fraction samples were dissolved in Buffer A [0.5\% Nonidet P-40, 0.5\% deoxycholate, $10 \mathrm{mM}$ Tris- $\mathrm{HCl}$ (pH 7.4), $0.1 \%$ SDS, $150 \mathrm{mM} \mathrm{NaCl}$ and $2 \mathrm{mM}$ phenylmethanesulfonyl fluoride] and mixed with an equal volume of $2 \mathrm{X}$ sodium dodecyl sulfate (SDS) sample buffer [180 mM Tris-HCl (pH 6.8), 39\% glycerol, 4\% SDS, 10\% 2mercaptoethanol and bromophenol blue] before denaturation for $5 \mathrm{~min}$. The mixture was electrophoresed with SDS-polyacrylamide gel electrophoresis (PAGE) for $2 \mathrm{~h}$ at room temperature. For immunoblotting, proteins were electrophoretically transferred to polyvinylidene difluoride (PVDF) transfer membranes (Amersham Biosciences Co. Ltd., Tokyo) previously blocked with Block Ace (Dainippon Pharmaceutical Co., Ltd., Tokyo, Japan) for $1 \mathrm{~h}$ at room temperature (RT) before further reaction with anti-IA-2ß mAbs for $1 \mathrm{~h}$ at RT. After washing thrice with PBS/0.1\% Tween-20 (PBS-T), the membranes were incubated with horseradish peroxidase (HRP)-conjugated anti-mouse IgG sheep $\mathrm{F}\left(\mathrm{ab}^{\prime}\right)_{2}$ fragment (Amersham Biosciences Co. Ltd.) for $1 \mathrm{~h}$ at RT, and then washed four times with PBS-T. The labeled bands were revealed with chemiluminescence using an enhanced chemiluminescence (ECL) detection reagent before exposure to Hyperfilm-MP (both from Amersham Biosciences Co. Ltd.). 
Immunoprecipitation. All procedures were performed at $4^{\circ} \mathrm{C}$ unless specified otherwise. $I A-2 \beta^{-/}$and $I A-2 \beta^{+/+}$mouse brains were solubilized in Buffer A. An affinity matrix was prepared by mixing $1 \mu \mathrm{g}$ affinity-purified mAb with $5 \mu \mathrm{g}$ Protein G Sepharose 4 Fast Flow (Amersham Biosciences Co. Ltd.) at RT. The brain lysate was then incubated with antibody-coated beads for $2 \mathrm{~h}$ before washing 3 times with PBS-T. Bound proteins of the lysate were eluted after boiling for $5 \mathrm{~min}$ in SDS sample buffer. The samples were analyzed by SDS-PAGE and Western blotting.

Immunoaffinity purification. All procedures were performed at $4^{\circ} \mathrm{C}$ unless specified otherwise. The membrane fraction corresponding to one $I A-2 \beta^{-/-}$mouse or $I A-2 \beta^{+/+}$mouse brain was solubilized in Buffer A. Samples were then subjected to low-speed centrifugation $(3,000 \mathrm{xg})$ for $1 \mathrm{~h}$ and the supernatant was incubated with $50 \mu \mathrm{g}$ Protein G Sepharose 4 Fast Flow for $1 \mathrm{~h}$. An affinity matrix was prepared by mixing $25 \mu \mathrm{g}$ type-3 mAb (WT4) or $100 \mu \mathrm{g}$ type-1 mAb (KO25) with $50 \mu \mathrm{g}$ Protein G Sepharose 4 Fast Flow at RT. The precleared membrane fractions of brain lysates or MIN6 cells were incubated with the antibody-coated beads for $1 \mathrm{~h}$. The beads were centrifuged at a low speed $(3,000 \mathrm{x} \mathrm{g}, 30 \mathrm{sec})$, supernatants were discarded, and the pellet was incubated again in another precleared membrane fraction. This reaction with the antibody-coated beads was repeated four times to establish a sample amounting to five brains or $5 \times 10^{7}$ MIN6 cells. The beads were washed thrice with Buffer A, and twice with PBS-T. Bound proteins of the lysate were eluted after boiling for $5 \mathrm{~min}$ in 2X SDS sample buffer [180 mM Tris$\mathrm{HCl}$ (pH 6.8), 3.9\% glycerol, 4\% SDS, 10\% 2-mercaptoethanol and bromophenol blue]. Proteins were electrophoresed on $8 \%$ polyacrylamide gel before transferring to a PVDF membrane (Nihon Millipore Co. Ltd., Tokyo).

$N$-terminal sequencing. The proteins on the PVDF membrane were visualized by staining with Coomassie brilliant blue $\mathrm{R}-250$. Individual protein bands were cut out and subjected to Edman degradation with the Procise 494 cLC sequencing system (Applied Biosystems, USA) for analysis of the Nterminal amino acid sequences.

Glycosidase digestion. IA $-2 \beta^{+/+}$or $I A-2 \beta^{-/-}$mouse brains were dissolved in Buffer A. The lysate was incubated in denaturing buffer $(0.5 \%$ SDS and $1 \%$ B-mercaptoethanol) for $10 \mathrm{~min}$ at $100^{\circ} \mathrm{C}$, treated with $50 \mathrm{mM}$ sodium phosphate $(\mathrm{pH} 7.5)$ and $1 \%$ Nonidet P-40 before adding $100 \mathrm{U}$ of peptide $\mathrm{N}$ glycosidase F (PNGase F) (New England Biolabs, MA, USA), while negative controls were not subjected to PNGase $\mathrm{F}$ treatment. The treated samples were further subjected to incubation for $2 \mathrm{~h}$ at $37^{\circ} \mathrm{C}$. After glycosidase digestion, the incubated samples were treated with SDS-PAGE sample buffer and boiled for $5 \mathrm{~min}$. The samples were then analyzed by SDS-PAGE and Western blotting.

Immunohistochemistry. NOD and ICR mice were sacrificed by excessive ether anesthesia and their pancreata were removed. The tissues were immersed overnight at $4^{\circ} \mathrm{C}$ in $4 \%$ paraformaldehyde EM (TAAB Laboratories Equipment Ltd., Berkshire, UK) in PBS. After washing with distilled water,

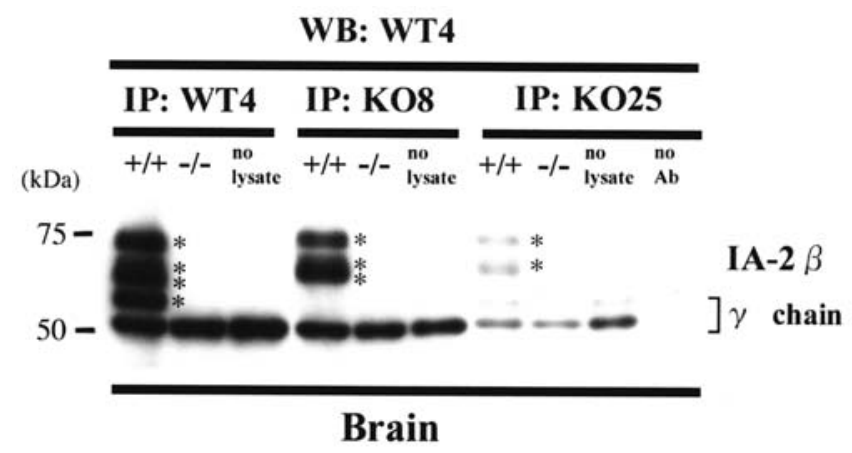

Figure 2. Immunoprecipitation of IA-2ß. Immunoprecipitation (IP) from brain extracts was performed by three types of monoclonal antibodies (mAbs; WT4, KO8 and KO25). Precipitated proteins from $I A-2 \beta^{+/+}$mouse brain $(+/+), I A-2 \beta^{-/-}$mouse brain (-/-) with non-brain lysate as a negative control (non-lysate), and antibody-free $I A-2 \beta^{+/+}$mouse brain as a negative control (non-Ab) were lysed in SDS sample buffer and separated on $8 \%$ SDS-PAGE gels. Western blotting (WB) was performed by ascites of WT4 diluted to 1:10000 with PBS-T and HRP-conjugated anti-mouse IgG sheep $\mathrm{F}\left(\mathrm{ab}^{\prime}\right)_{2}$ fragment (diluted to $1: 10000$ with PBS/0.1\% Tween-20 or PBS-T). The positions of precipitated IA-2B isoforms and the immunoglobulin $\gamma$ chain are indicated by asterisks (*) and a square bracket ( ]), respectively.

the pancreata were rinsed overnight at $4^{\circ} \mathrm{C}$ in ultra-pure water containing $20 \%$ (wt/vol) sucrose, and embedded in cryoprotector Tissue Tek (Sakura Finetechnical Co. Ltd., Tokyo) before being frozen in liquid nitrogen. Cryostat sections (12- $\mu \mathrm{m}$ thick) were sliced and mounted on MAS-coated slide glass, and air dried. The sections were first incubated with PBS-T for $5 \mathrm{~min}$ followed by another $30 \mathrm{~min}$ before being autoclaved in $0.01 \mathrm{M}$ sodium citrate at $121^{\circ} \mathrm{C}$ for $20 \mathrm{~min}$. The sections were rinsed thrice with PBS-T ( $5 \mathrm{~min} /$ wash). Endogenous peroxidase was blocked by treatment with $0.3 \% \mathrm{H}_{2} \mathrm{O}_{2}$ in methanol for $30 \mathrm{~min}$. After washing thrice with PBS-T, the sections were blocked with Block Ace for $1 \mathrm{~h}$ at RT, and the sections were thereafter incubated overnight at $4{ }^{\circ} \mathrm{C}$ with primary antibodies WT4 and KO8 from the hybridoma culture supernatants. The sections were washed thrice with PBS-T and labeled with secondary antibodies, Histofine Simple Stain MAX PO (M) (Nichirei Corporation, Tokyo). After washing 4 times with PBS-T, the antibody reaction was visualized using Histofine Simple Stain 3'-diaminobenzidine tetrahydrochloride (DAB) (Nichirei Corporation). Sections were counterstained with hematoxylin, dehydrated and mounted for histological examination with light microscopy.

\section{Results}

IA-2 $\beta: 4$ different kinds of isoforms indicated by novel $m A b s$. The existence of IA $-2 \beta$ isoforms was confirmed with immunoprecipitation using the mouse brain. Of the 4 isoforms of 60- (IA-2ß60), 64- (IA-2ß64), 67- (IA-2ß67) and 71-kDa (IA-2ß71) proteins detected by WT4 (Fig. 2); IA-2B64, IA-2ß67 and IA-2B71 were precipitated by KO8, IA-2B67 and IA-2ß71 were precipitated by KO25, while IA-2B60 was non-reactive with either $\mathrm{KO} 8$ or $\mathrm{KO} 25$. The bands were not observed in the negative controls of $I A-2 \beta^{-/-}$mice; either without brain lysate or without antibodies. These results suggest that IA-2ß was composed of at least 4 isoforms. As IA-2ß67 and IA-2ß71 were detected by both KO8 and KO25 

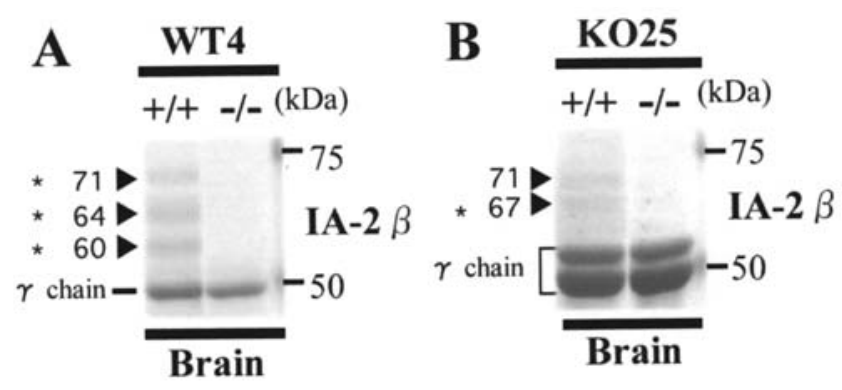

Figure 3. Affinity-purified IA-2ß isoforms from the mouse brain. Affinitypurified proteins from the mouse brain with WT4 (A) and KO25 (B) were electrophoresed on $8 \%$ SDS-PAGE gels and transferred to PVDF membranes. The purified proteins from $I A-2 \beta^{+/+}$mouse brain $(+/+)$and $I A-$ $2 \beta^{-/}$mouse brain (-/-) were stained with Coomassie brilliant blue R-250 as negative controls. Arrow heads show positive staining of IA-2ß. Immunoglobulin $\gamma$ chains and the bands $(*)$ used for the N-terminal sequence analysis are indicated accordingly.

\section{$41471 \mathrm{kDa} \mathrm{LA-2}$ \\ $412 \stackrel{455}{\text { KEQPEEVLSSEEETAGVEHVRSRYSKDLFERKNSEPQPRR }}$

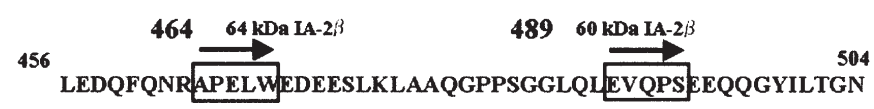

Figure 4. Alignment of N-terminal sequences obtained from IA-2ß isoforms with the predicted amino acid sequence from the translated IA-2B gene. The amino acid sequence 412-504 was predicted from IA-2ß cDNA. The numbers of the respective amino acid residues are shown above the sequences. The N-terminal amino acid sequences of IA-2B isoforms obtained by Edman degradation are boxed. The start of IA-2B protein expression is represented by arrows. The predicted cleavage (KK) site is underlined.

and similarly precipitated by WT4, these 2 isoforms might harbor a recognition site(s) for the $3 \mathrm{mAb}$ subtypes corresponding to residues 414-534. Although precipitated by WT4 and KO8, IA-2ß64 was not affected by KO25, thus suggesting that this isoform might have lost the recognition site for KO25 (including residues 456-470). In the case of WT4-detectable IA-2ß60, the fact that it was not precipitated by $\mathrm{KO} 8$ or KO25 suggested that IA-2B60 might have lost the recognition site(s) for $\mathrm{KO} 8$ and $\mathrm{KO} 25$ (including residues 456-493). This immunoprecipitation analysis confirmed that IA-2 $\beta$ was composed of at least 4 isoforms in the mouse brain. As IA-2B60 and IA-2B64 had respectively lost the residues 456-470 and 456-493, certain sites/regions in IA-2B were probably proteolytically cleaved. As such, sequencing of the N-terminal amino acid was performed to determine the cleavage site(s) of IA- $2 \beta$ isoforms. Prior to $\mathrm{N}$-terminal amino acid sequencing, isoforms IA-2B60, IA-2B64 and IA-2B71 were purified by immunoprecipitation using WT4 (Fig. 3A). For sequencing of IA-2ß67, immunoaffinity purification with KO25 was performed (Fig. 3B). To note, IA-2ß60, IA-2ß64 and IA-2ß71 proteins, which were not observed in the $I A-2 \beta^{-1-}$ mouse brain, were located in protein samples from the $I A$ $2 \beta^{+/+}$mouse brain (Fig. 3A, arrow heads). Moreover, IA$2 \beta 67$ and IA-2ß71 proteins, not detected in protein samples from the $I A-2 \beta^{-1-}$ mouse brain, were observed in protein

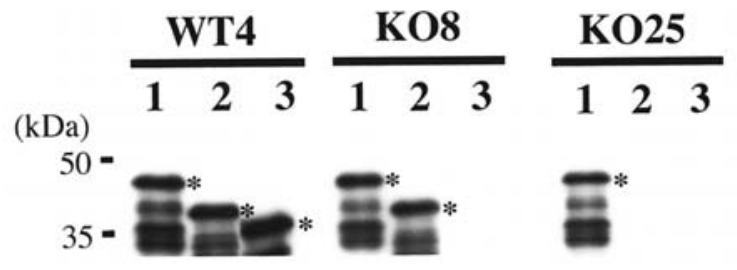

IA-2 $\beta$

Figure 5. Western blott analysis of recombinant IA-2ß isoforms Biotinylated recombinant IA-2B proteins (see Fig. 1) were dissolved with ultra-pure water and separated into lanes on a $10 \%$ SDS-PAGE gel: IA-2B (414-717) (lane 1), IA-2ß (464-717) (lane 2) and IA-2ß (489-717) (lane 3). Following transfer onto a PVDF membrane, Western blotting was performed with the indicated mAbs, and hybridoma culture supernatants were diluted to $1: 10$ before use. HRP-conjugated anti-mouse IgG sheep $\mathrm{F}\left(\mathrm{ab}^{\prime}\right)_{2}$ fragment (diluted to 1:20,000) was used as a secondary antibody. The bands (*) with predicted sizes of recombinant IA-2 3 protein are indicated accordingly.

samples from the $I A-2 \beta^{+/+}$mouse brain (Fig. 3B, arrow heads). These data showed that purified 2-pmol samples of IA-2ß60, IA-2ß64, IA-2ß67 and IA-2ß71 were sufficient for staining with Coomassie brilliant blue stain in the $\mathrm{N}$-terminal amino acid sequence analysis.

Locating the amino acid sequence of $N$-terminal cleavage site(s) of isoforms with Edman digestion. Purified IA-2B60, IA-2ß64, IA-2ß67 and IA-2ß71 kDa (Fig. 3, asterisks) were isolated and subjected to Edman digestion to define their respective $\mathrm{N}$-terminal cleavage sites. The first $5 \mathrm{~N}$-terminal amino acid sequences of IA-2B60, IA-2B64 and IA-2B71 were analyzed accordingly (Fig. 4). The first 5 residues of IA-2B71 of the brain were sequenced as Ser-Glu-Gln-ProGlu. Sequences Glu-Val-Gln-Pro-Ser and Ala-Pro-Glu-LeuTrp were obtained from IA-2B60 and IA-2ß64 of the brain, respectively. Sequence Glu-Val-Gln-Pro-Ser was obtained from isoform IA-2B60 of MIN6 cells. However, the sequence(s) of IA-2ß67 was not determined.

On aligning the $\mathrm{N}$-terminal sequences of these IA-2B isoforms with the deduced amino acid sequences (Fig. 4), sequences Ser-Glu-Gln-Pro-Glu and Ala-Pro-Glu-Leu-Trp of IA-2ß64 and IA-2ß71 corresponded to the predicted amino acid residues 414-418 and 464-468, respectively. Furthermore, sequence Glu-Val-Gln-Pro-Ser of IA-2B60 kDa IA-2B was identical to the predicted amino acid residues 489-493. These results revealed that the N-termini of IA-2B60, IA-2ß64 and IA-2ß71 were $\mathrm{Glu}^{489}$, $\mathrm{Ala}^{464}$ and $\mathrm{Ser}^{414}$, respectively.

Recombinant IA- $2 B$ protein was reacted with $\mathrm{mAb}$ to ascertain that IA- $2 B$ isoforms starting from $\mathrm{Ala}^{464}$ would be IA-2B64 and not IA-2ß67. Recombinant IA-2ß proteins starting from the respective N-termini of IA-2ß60, IA-2ß64 and IA-2B71 isoforms were obtained as schematically represented in Fig. 1. IA-2ß (414-717), IA-2ß (464-717) and IA-2ß (489-717) were expressed from $\mathrm{Ser}^{414}, \mathrm{Ala}^{464}$ and $\mathrm{Glu}^{489}$, which actually were the N-terminal sites of IA-2B71, IA-2B64 and IA-2ß60, respectively The estimated respective molecular sizes of IA-2ß (414-717), IA-2ß (464-717) and IA-2B (489$717)$ were 46,41 and $38 \mathrm{kDa}$. Western blotting using recombinant IA-2B isoforms (Fig. 5) demonstrated that the $46-\mathrm{kDa}$ band was detected by WT4, KO8 and KO25, the 41$\mathrm{kDa}$ band was detected by WT4 and $\mathrm{KO} 8$, while the $38-\mathrm{kDa}$ 


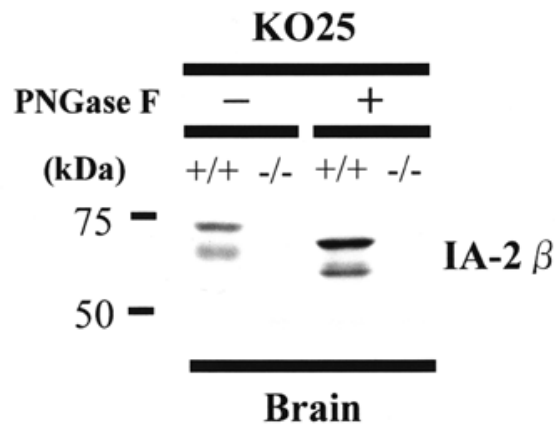

Figure 6. PNGase F treatment analysis. $I A-2 \beta^{+/+}$mouse $(+/+)$and $I A-2 \beta^{-1-}$ mouse (-/) brain lysates were treated with (+) or without (-) PNGase F. Samples were electrophoresed on $8 \%$ SDS-PAGE gel, followed by immunoblotting with KO25 hybridoma culture supernatant (diluted to 1:20 with PBS-T). HRP-conjugated anti-mouse IgG sheep F ( $\left(\mathrm{bb}^{\prime}\right)_{2}$ fragment was diluted to 1:20,000 and used as a secondary antibody.

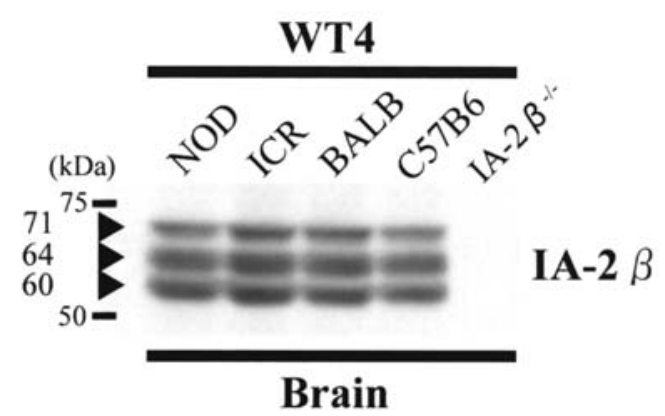

Figure 7. Western blott analysis of IA- $2 \beta$ isoform expression in NOD mouse brains. Membrane fractions from NOD, ICR, BALB/C, C57BL and $I A-2 \beta^{-1-}$ mouse brains were lysed in Buffer A. SDS-PAGE on $8 \%$ polyacrylamide gel electrophoresis and Western blotting were then performed. Purified $\mathrm{mAb}$ WT4 $(1 \mu \mathrm{g} / \mathrm{ml})$ was used as the primary antibody. HRP-conjugated antimouse $\operatorname{IgG}$ sheep $\mathrm{F}\left(a b^{\prime}\right)_{2}$ fragment was diluted to $1: 20,000$ and used as the secondary antibody. Arrow heads show the detectable bands of the 60-, 64and 71-kDa isoform proteins on blotting.

band was detected by only WT4. These data confirmed that IA-2ß (464-717) was detected by KO8 but not by KO25. Since IA-2ß67 was supposedly detected by KO25, the IA-2ß isoform starting from $\mathrm{Ala}^{464}$ might represent IA-2ß64 but not IA-2ß67. Taken together, these results suggest that the differences in isoforms IA-2B60, IA-2B64 and IA-2B71 probably resulted from cleavages at the relevant specific sites in the extracellular domain of IA-2ß.

PNGase digestion affected the molecular weight of isoforms. To determine if the difference between IA-2B67 and IA-2B71 kDa IA- $2 \beta$ was caused by $N$-linked glycosylation, IA- $2 \beta$ was treated with PNGase F to remove the carbohydrates at the $N$ glycosylation sites (Fig. 6). The 67- and 71-kDa bands were detected by $\mathrm{KO} 25$ in PNGase F-free lysate. In PNGase Ftreated lysates, the $65-$ and $69-\mathrm{kDa}$ bands were detected by $\mathrm{KO} 25$. No bands were observed in the $I A-2 \beta^{--}$mouse brain lysate with or without PNGase F. PNGase F treatment yielded band shifts in IA-2B60, IA-2B64, IA-2B67 and IA$2 \beta 71$ (data not shown). These results demonstrated that the IA-2ß isoforms were $N$-linked glycosylated and the difference

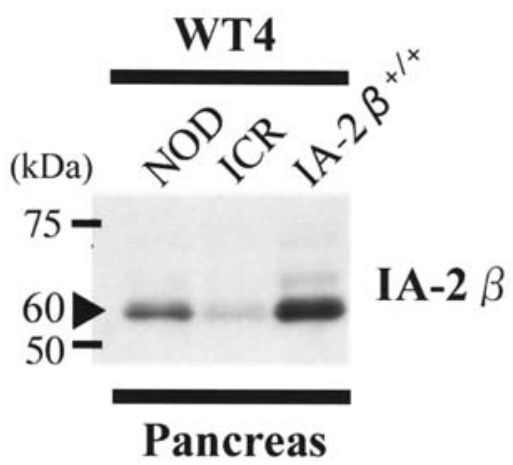

Figure 8. Western blott analysis of IA-2ß isoform expression in the NOD mouse pancreas. The membrane fraction of the pancreas of NOD, ICR and $I A-2 \beta^{+/+}$mice were thawed in Buffer A before SDS-PAGE on $8 \%$ polyacrylamide gel electrophoresis and Western blotting were performed. Purified mAb WT4 $(1 \mu \mathrm{g} / \mathrm{ml})$ was used as the primary antibody, while HRPconjugated anti-mouse IgG sheep $\mathrm{F}\left(\mathrm{ab}^{\prime}\right)_{2}$ fragment (diluted to 1:20,000) was used as the secondary antibody. Arrow heads discriminate the position of $60-\mathrm{kDa}$ proteins on the blot.

between IA-2ß67 and IA-2ß71 was not attributable to $\mathrm{N}$ linked oligosaccharides.

Absence of abnormal isoforms of IA- $2 \beta$ in NOD mice. The NOD mouse is the most widely used animal model for human type-1 autoimmune diabetes. Western blotting and immunohistochemistry were employed to verify if abnormal isoform expression occurred in NOD mice. The major 60-, 64- and $71-\mathrm{kDa}$ bands were detected in the NOD mouse brain, a finding similarly observed in control (ICR, BALB or C57BL) mouse brains (Fig. 7). These three bands were not observed in the $I A-2 \beta^{-/-}$mouse brain. This result showed that the main IA- $2 \beta$ isoforms produced were IA-2ß60, IA-2ß64 and IA-2ß71 in the NOD mouse brain as well as in the controls. As detected in the ICR and $I A-2 \beta^{+/+}$mice (Fig. 8), predominant expression of the $60-\mathrm{kDa}$ band was similarly detected in the NOD mouse pancreas. It is noteworthy that IA-2ß was mainly expressed as the $60-\mathrm{kDa}$ isoform in the pancreas of NOD mice and controls. Western blott analysis disclosed no difference in the isoform expression pattern between NOD and control mice.

These observations were, in fact, confirmed by immunohistochemistry. In ICR mouse pancreatic islets, brown staining was detected by WT4 in most islet cells (Fig. 9D), whereas staining by KO 8 was observed more predominantly in peripheral than core cells of the islets (Fig. 9E). In the NOD mouse, WT4 staining was detected in most islet cells (Fig. 9A), albeit the positive KO8-staining response was manifested more predominantly in peripheral than core cells of the islets (Fig. 9B). No staining was demarcated in the islets reacted without antibodies in ICR (Fig. 9F) and NOD (Fig. 9C) mice, suggesting that the NOD mouse displayed an IA-2B isoformstaining pattern in the islets similar to that of the ICR mouse. IA-2ß in MIN6 was consistently recognized by WT4 but not by KO8 (data not shown), and $B$ cells were located in the core regions of the islets. These results thus indicated that IA$2 \beta 60$ was expressed in the $B$ cells of NOD and control mouse pancreatic islets, although IA-2B64, IA-2B67 and IA-2B71 were not noted. With reference to the IA- $2 B$ isoform 


\section{WT4 KO8 Control}

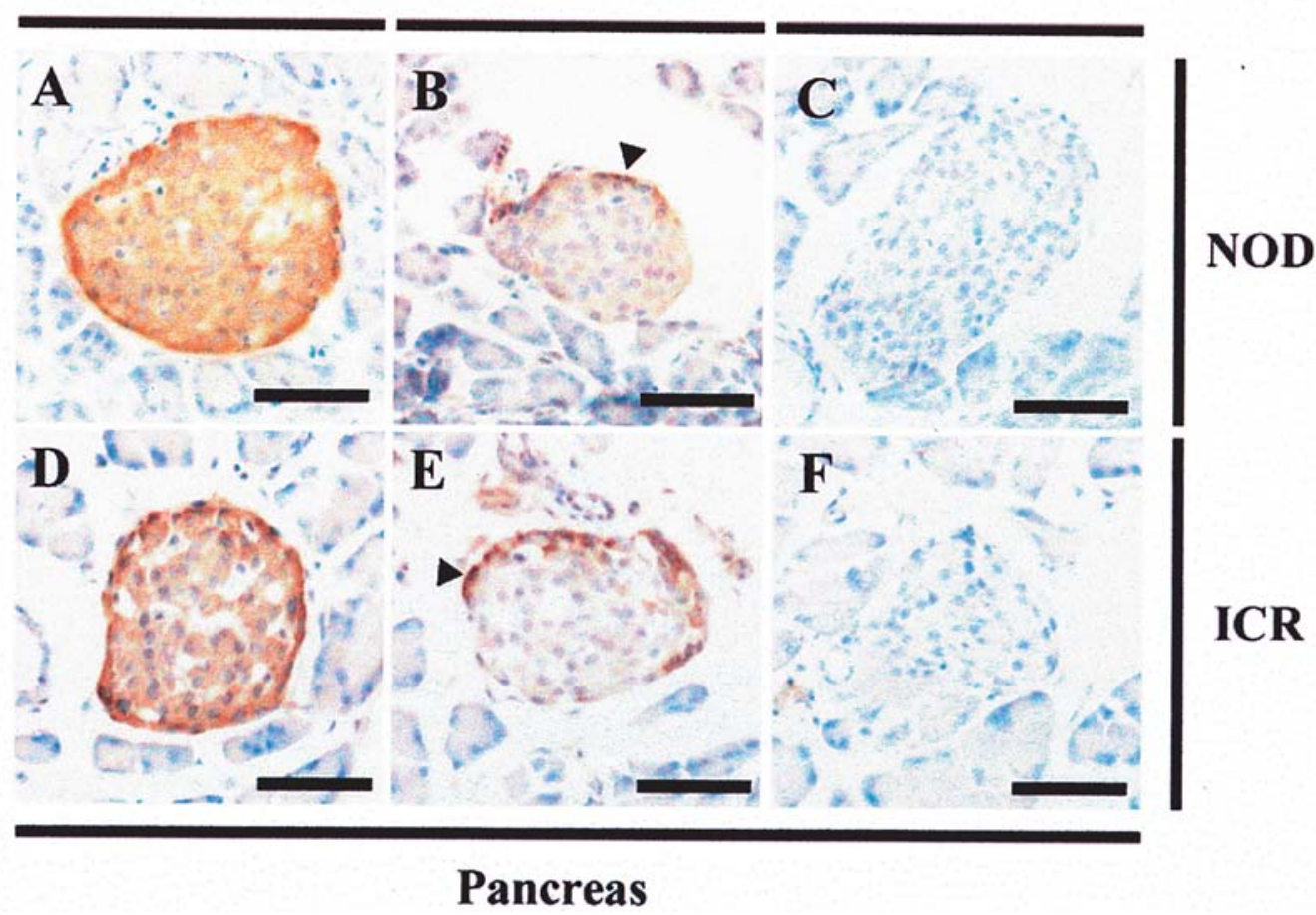

Figure 9. Immunohistochemical analysis of IA-2ß isoforms in the NOD mouse pancreatic islet. Pancreatic sections of NOD (A-C) and ICR mice (D-F) were analyzed for isoform expression of IA-2ß detectable with WT4 (A, D) and KO8 (B, F) hybridoma culture supernatant respectively, while antibody-free samples (C, F) were used as negative controls. Antibody binding was visualized with peroxidase-conjugated brown staining (arrow heads) and counterstaining with hematoxylin (blue nuclear labeling). Bars, $50 \mu \mathrm{m}$.

expression pattern in the islets, pancreas and brain, the NOD mouse revealed no significant difference compared with controls.

\section{Discussion}

Although IA-2ß mRNA is well-expressed in neuroendocrine tissues such as pancreatic islets and brain neurons $(1,2,5)$, very little is known about the role of IA- $2 \beta$ expression in the brain. This study sheds light on the post-translational processing of mIA- $2 B$ in mouse brains. Our studies demonstrated that the isoform IA- $2 B$ in the various strains of mouse was expressed with different molecular weights in 4 isoforms; IA-2ß60, IA-2ß64, IA-2ß67 and IA-2B71. The difference in these IA- $2 \beta$ isoforms was indicated by three methods: i) immunoprecipitation, ii) $\mathrm{N}$-terminal amino acid sequencing, and iii) $\mathrm{N}$-glycosylation analysis. This study demonstrated that mIA-2ß was subjected to at least three cleavages at specific sites.

Immunoprecipitation showed that IA- $2 B$ predominantly consisted of 4 isoforms; IA-2ß60, IA-2ß64, IA-2ß67 and IA$2 \beta 71$. The finding that $\mathrm{mAbs}$ with different epitope regions displayed specific isoform recognition patterns indicates that IA-2B is definitely subjected to proteolytic cleavages. According to the $\mathrm{N}$-terminal amino acid sequence, the primary structures of IA- $2 \beta$ isoforms were determined. Note that the $\mathrm{N}$-terminal sequence of purified IA-2ß71 (Ser-Glu-Gln-ProGlu) corresponded well to residues 414-418, as predicted from the IA-2B genomic DNA (Fig. 4). As such, cleavage between Lys $^{413}$ and Ser ${ }^{414}$ would produce IA-2ß71. Post- translational processing of molecules in the secretory pathway commonly occurs at sites marked by clusters of basic amino acids; viz., prohormone convertase 1 and 2 cleave at a site typically marked by double or single basic amino acids $(15,16)$. Cleavage after the KK site (residues 412 and 413) agrees well with the dibasic consensus sequence recognized by the prohormone convertase. Thus, cleavage that yielded IA-2ß71 would have likely been achieved with prohormone convertase. To our knowledge, the present study demonstrated for the first time that a putative cleavage of IA- $2 B$ did exist after the KK site.

The N-terminal sequence of purified IA-2B64 (Ala-ProGlu-Leu-Trp) was identical to residues 464-468, as predicted from the IA-2ß genomic DNA (Fig. 4). In the present study, isoform mIA-2ß was cleavaged between $\mathrm{Arg}^{463}$ and $\mathrm{Ala}^{464}$, yielding the 64-kDa C-terminal fragment. Since Arg ${ }^{463}$ cleavage coincided well with the single basic consensus sequence recognized by the prohormone convertase, most likely the same enzyme was responsible for the cleavage between $\mathrm{Arg}^{463}$ and $\mathrm{Ala}^{464}$. A novel processing site that produced the IA-2ß isoform was identified as well.

The N-terminal sequence of purified IA-2ß60 (Glu-ValGln-Pro-Ser) was consistent with residues 489-493, as predicted from the IA- $2 \beta$ genomic DNA. Isoform mIA- $2 \beta$ was found to have been cleavaged between $\mathrm{Leu}^{488}$ and $\mathrm{Glu}^{489}$ to generate a $60-\mathrm{kDa} \mathrm{C}$-terminal fragment.

Despite conducting several bioinformatic searches, we located no processing enzymes that could recognize the neighboring sequences around $\mathrm{Glu}^{489}$ in neuroendocrine tissues. IA-2ß60 was probably processed by unidentified 
endopeptidases, implying that novel unknown processing enzyme(s) might have existed in the neuroendocrine tissues.

This study failed to determine the N-terminus of IA-2B67. Besides IA-2ß67 and IA-2ß71 (Fig. 4), both IA-2ß60 and IA-2B64 (data not shown) also exhibited increased migration rates during SDS-PAGE after PNGase F treatment, implying IA-2ß67 was probably not derived from the non-glycosylation of IA-2B71. In addition, this study did not identify the processing mechanism of IA-2B67. Alternative splicing would not be likely because reverse transcription-PCR indicated a single RNA band in the mouse brain (data not shown). Therefore, IA-2ß67 might have been produced by a proteolytic cleavage of the amino acid sequence along residues 415-463.

Data in the present study revealed that the processing of mIA- $2 B$ in the mouse brain was apparent. Since it possessed the signal peptide sequence encompassing residues 1-26, IA$2 \beta$ should have been processed in the endoplasmic reticulum as a pre-protein. Post-translational modifications of IA- $2 \beta$ were able to yield at least 4 IA-2B isoforms, and at least three were probably produced by specific proteolytic cleavages of the luminal domain; i.e., between $\mathrm{Lys}^{413}$ and $\mathrm{Ser}^{414}$, between $\mathrm{Arg}^{463}$ and $\mathrm{Ala}^{464}$ and between $\mathrm{Leu}^{488}$ and $\mathrm{Glu}^{489}$. The respective molecular weights of regions 414-1001, 464-1001 and 489-1001 were estimated to be 57-, 60- and 66-kDa, respectively. Estimations of the expression region and $\mathrm{N}$ glycosylation account respectively for the observed molecular sizes of IA-2ß isoforms; viz., 60, 64 and $71 \mathrm{kDa}$. Hence, the expression regions of IA-2ß60, IA-2ß64 and IA-2ß71 seemed to respectively concur with residues 414-1001, 464-1001 and 489-1001.

From this primary structure, IA- $2 B$ isoforms were assumed to occupy the transmembrane region (residues 601621) and the PTP domain (residues 756-990). Besides each IA-2B isoform, different consensus sequences were presumed to exist (Fig. 4). Thus, the difference in the IA-2B isoforms could be due to certain specific cleavage enzymes. While mature IA-2B is located in dense-core granules (2), these cleavages are probably sited in the Golgi-complex or immature secretory granules; viz., the compartments where proteolytic cleavage of secretory granule proteins frequently occurs (17). Processing is significant for biological activities of many proteins. Several proteins, including receptor-type PTP, have to be proteolytically cleaved to generate associate ligands $(18,19)$. As such, the generation of IA-2B isoforms probably involved different ligands in certain granules. IA-2ß might play a role in granule formation by answering to the ligands.

For comparison purposes, the processing of IA- $2 B$ in other tissues must be investigated. It is of high priority to focus on IA- $2 \beta$ in the pancreatic $\beta$ cells, as this protein is an autoantigen in type- 1 diabetes. Although IA- $2 \beta$ in $\beta$ cells is post-translationally processed, the processing mechanism of IA- $2 B$ in $B$ cells remains unclear. Therefore, the processing mechanism of pancreatic $B$ cells in isoform IA-2 $B$ should thus be clarified. However, it is difficult to purify and sequence IA- $2 B$ in $B$ cells because of the limited amount of islet cell tissues that can be harvested and purified. As both $60-\mathrm{kDa}$ IA- $2 B$ in the pancreatic $B$ cell line and non-pancreatic IA$2 \beta 60$ were recognized only by WT4 (not by KO8 and KO25), IA- $2 \beta$ in $\beta$ cells might have an expressing region identical to that of IA-2ß60. In other words, IA-2 360 production by single processing might occur in $B$ cells. This study showed that IA-2B60 was processed between $\mathrm{Leu}^{488}$ and $\mathrm{Glu}^{489}$ by as yet unidentified processing enzymes. Therefore, IA- $2 \beta$ in $B$ cells is assumed to have been cleaved by unknown enzymes between $\mathrm{Leu}^{488}$ and $\mathrm{Glu}^{489}$ rather than at regions after the KK site. This study provided new insights on the primary structures of IA- $2 B$ in the mouse brain and $B$ cells. To understand the mechanism of the primary structure of IA- $2 \beta$ serving as an autoantigen in type- 1 diabetes, further metabolic studies of IA- $2 \beta$ are warranted.

In summary, this study revealed that brain mIA-2 $\beta$ underwent at least three specific proteolytic cleavages to generate the mIA- $2 \beta$ isoforms, where mature IA- $2 \beta$ isoforms would harbor the PTP domain. Regarding the isoforms, the diversity of the extracellular domain may correspond to multiple ligands, and the common intracellular domain may preserve the function in the form of PTP. To elucidate the exact functions and pathological roles of IA- $2 \beta$, it is necessary to characterize the relevant processing enzymes, ligands and biochemical activities of IA-2ß. In addition, sound knowledge on features of the primary structure of IA- $2 B$ will facilitate a better understanding of IA- $2 \beta$ action in the signal pathway(s) regulating relevant hormonal secretions related to type-1 diabetes.

\section{Acknowledgements}

We appreciate Dr Notkins of the National Institute of Health, USA, for the kind gift of $I A-2 \beta^{-/-}$mice. Thanks are due to Dr Anthony Foong for reading the manuscript.

\section{References}

1. Lu J, Li Q, Xie H, Chen ZJ, Borovitskaya AE, Maclaren NK, Notkins AL and Lan MS: Identification of a second transmembrane protein tyrosine phosphatase, IA-2beta, as an autoantigen in insulin-dependent diabetes mellitus: precursor of the 37-kDa tryptic fragment. Proc Natl Acad Sci USA 93: 2307-2311, 1996.

2. Wasmeier C and Hutton JC: Molecular cloning of phogrin, a protein-tyrosine phosphatase homologue localized to insulin secretory granule membranes. J Biol Chem 271: 18161-18170, 1996

3. Chiang MK and Flanagan JG: PTP-NP, a new member of the receptor protein tyrosine phosphatase family, implicated in development of nervous system and pancreatic endocrine cells. Development 122: 2239-2250, 1996.

4. Smith PD, Barker KT, Wang J, Lu YJ, Shipley J and Crompton MR: ICAAR, a novel member of a new family of transmembrane, tyrosine phosphatase-like proteins. Biochem Biophys Res Commun 229: 402-411, 1996.

5. Li Q, Borovitskaya AE, DeSilva MG, Wasserfall C, Maclaren NK, Notkins AL and Lan MS: Autoantigens in insulin-dependent diabetes mellitus: molecular cloning and characterization of human IA-2 beta. Proc Assoc Am Physicians 109: 429-439, 1997.

6. Notkins AL, Zhang B, Matsumoto Y and Lan MS: Comparison of IA-2 with IA-2beta and with six other members of the protein tyrosine phosphatase family: recognition of antigenic determinants by IDDM sera. J Autoimmun 10: 245-250, 1997.

7. Fitzgerald LR, Walton KM, Dixon JE and Largent BL: PTP NE-6: a brain-enriched receptor-type protein tyrosine phosphatase with a divergent catalytic domain. J Neurochem 68 : $1820-1829,1997$

8. Lu J, Notkins AL and Lan MS: Isolation, sequence and expression of a novel mouse brain cDNA, mIA-2, and its relatedness to members of the protein tyrosine phosphatase family. Biochem Biophys Res Commun 204: 930-936, 1994. 
9. Notkins AL, Lan MS and Leslie RD: IA-2 and IA-2beta: the immune response in IDDM. Diabetes Metab Rev 14: 85-93, 1998.

10. Gepts W and Lecompte PM: The pancreatic islets in diabetes. Am J Med 70: 105-115, 1981.

11. Kawasaki E, Eisenbarth GS, Wasmeier C and Hutton JC: Autoantibodies to protein tyrosine phosphatase-like proteins in type I diabetes: overlapping specificities to Phogrin and ICA512/IA-2. Diabetes 45: 1344-1349, 1996.

12. Kubosaki A, Gross S, Miura J, Saeki K, Zhu M, Nakamura S, Hendriks W and Notkins AL: Targeted disruption of the IA2 beta gene causes glucose intolerance and impairs insulin secretion but does not prevent the development of diabetes in NOD mice. Diabetes 53: 1684-1691, 2004.

13. Kearney JF, Radbruch A, Liesegang B and Rajewsky K: A new mouse myeloma cell line that has lost immunoglobulin expression but permits the construction of antibody-secreting hybrid cell lines. J Immunol 123: 1548-1550, 1979.

14. Miyazaki J, Araki K, Yamato E, Ikegami H, Asano T, Shibasaki Y, Oka Y and Yamamura K: Establishment of a pancreatic beta cell line that retains glucose-inducible insulin secretion: special reference to expression of glucose transporter isoforms. Endocrinology 127: 126-132, 1990.
15. Halban PA and Irminger JC: Sorting and processing of secretory proteins. Biochem J 299: 1-18, 1994.

16. Seidah NG, Chretien M and Day R: The family of subtilisin/ kexin like pro-protein and pro-hormone convertases: divergent or shared functions. Biochimie 76: 197-209, 1994.

17. Orci L, Ravazzola M, Amherdt M, Perrelet A, Powell SK, Quinn DL and Moore HP: The trans-most cisternae of the Golgi complex: a compartment for sorting of secretory and plasma membrane proteins. Cell 51: 1039-1051, 1987.

18. Jiang YP, Wang H, D'Eustachio P, Musacchio JM, Schlessinger J and Sap J: Cloning and characterization of R-PTP-kappa, a new member of the receptor protein tyrosine phosphatase family with a proteolytically cleaved cellular adhesion molecule-like extracellular region. Mol Cell Biol 13: 2942-2951, 1993.

19. Serra-Pages C, Saito H and Streuli M: Mutational analysis of proprotein processing, subunit association, and shedding of the LAR transmembrane protein tyrosine phosphatase. J Biol Chem 269: 23632-23641, 1994. 